International Journal of Power Electronics and Drive System (IJPEDS)

Vol. 11, No. 2, June 2020, pp. 667 676

ISSN: 2088-8694, DOI: 10.11591/ijpeds.v11.i2.pp667-676

\title{
Feasibility analysis of standalone PV powered battery using SEN for smart grid
}

\author{
Syed Zahurul Islam ${ }^{1}$, Mohammad Lutfi Othman², Norman Mariun ${ }^{3}$, Hashim Hizam ${ }^{4}$, Nur Ayuni ${ }^{5}$ \\ ${ }^{1}$ Department of Electrical Engineering, Faculty of Electrical \& Electronics Engineering, Universiti Tun Hussein Onn \\ Malaysia, Malaysia \\ 2,3,4,5 Advanced Lightning, Power and Energy Research (ALPER), Department of Electrical and Electronics Engineering, \\ Faculty of Engineering, Universiti Putra Malaysia, Malaysia
}

\begin{abstract}
In Smart Grid (SG) communication network, sensors integrated communication radios namely ZigBee, $\mathrm{Wi}-\mathrm{Fi}$, and Bluetooth are becoming urgent and crucial part of SG wireless communication. Sensor nodes are generally battery powered. With the enhancement and huge utilization of sensor technologies, batteries have not been improved significantly at the same pace. However, batteries are essential to power the sensor nodes and there is no alternative of this energy bank. Therefore, to provide seamless power to the nodes is a challenge when the nodes are meant for integrating distributed renewable generations for years. Necessitate of the battery replacement is not often cost effective when the batteries are drained out. This paper presents a feasibility study of standalone Photovoltaic (PV) powered battery using Sensors-radios integrated Embedded Node (SEN) for SG application. In this study, we have analyzed charging characteristics of a lead-acid battery that can be recharged during day time by a PV module. The aim of this research is to testify the two simultaneous jobs- (i) the battery is sufficient to power Sensors-ZigBee integrated Arduino (SZA) for at least one day operation, (ii) scrutiny the optimal size of PV for recharging the battery considering three different day variations- average, cloudy, and full rainy day. The result from real data analysis reveals that the module is sufficient to recharge the battery on an average day; however, it is not sufficient for full cloudy or full rainy day. Finally, a mathematical model is obtained from regression analysis that shows battery internal resistance is exponential to voltage on both full cloudy and rainy day, but it is linear on average day.
\end{abstract}

This is an open access article under the CC BY-SA license.

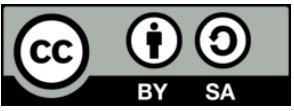

Corresponding Author:

Syed Zahurul Islam,

Dept. of Electrical Engineering

Faculty of Electrical \& Electronics Engineering, Universiti Tun Hussein Onn Malaysia,

Batu Pahat, Johor, Malaysia

Email: zahurul2003_du@yahoo.com

\section{INTRODUCTION}

With the development of wireless sensor and embedded system technologies, Smart Grid (SG) is becoming more popular, whereby it defines of altering the conventional grid by a modern, automated, emerging, robust, bidirectional, enhance sensors, Internet of things, and wireless communication technologies [1-3]. Hefty price of fossil fuel and its usage cripple our environment in the sense of carbon emissions; therefore, researchers and technologists are paying their efforts to enhance the tradition power industry by a smart power system or SG [4]. A range of wired and wireless technologies are relevant to SG communication 
networks including Cellular, RF Mesh, WLAN 802.11, WiMAX, ZigBee/ZigBeePRO, McMiLL, etc. which are integrated with Sensors-radios integrated Embedded Node (SEN) [3]. These wireless sensor technologies have become highly scalable, reliable, and low cost technology that it is suitable for various SG applications, such as distributed renewable energy management system [3-5], home energy management system [6, 7], last mile communication [8], energy distribution and management [9], smart and automatic metering [10], plug in electrical vehicle charging management system [11].

SEN is one of the pivotal parts in SG implementation. It is often battery-powered. It is unlikely that SEN can be powered by grid line to their remote deployment sites, for example distributed renewable energy generations - a significant application in SG [3]. While powered by the battery, SEN can be progressively damaged during their operational lifetime due to insufficient power supply, energy bank aging, and design error etc. $[1,2,12]$.

SEN provides a vital solution in the application of low power requirement. G. Tuna and V.C. Gungor have discussed extensively on different types of battery and energy harvesting techniques for SEN applications. The problem of powering copious batteries in industry applications is highlighted. The extend of battery life has been proposed by energy harvesting technologies such as solar, radio frequency vibration, thermal, and air flow where solar energy is considered as most profound energy harvesting solution [13]. A state-of-art technique was applied by [14] to analyze charging characteristics of a commercial lithium battery. The results exhibit that electrochemical phenomena, such as thermal effects, rate-capacity features, and charge recovery can play a role in WSN design parameters such as power levels and packet sizes. A similar type of research- battery discharge characteristics was conducted by [15]. Through the experimental data, the authors evaluated key performance factors, such as distance between two SENs, channel, and operating power in battery performance. A simulation-based energy saving algorithm for battery in WSN was proposed by [16]. The researchers found experimentally that duty cycle is vital factor for extending battery life. Increase in supplied voltage can increase the duty cycle of the battery, which in fact increases the battery life. However, the source of the supply voltage is not mentioned by the authors. Power attacks can cause the SEN to malfunction such as it is unable to send the packet to its destined SEN. Gelenbe analyzed the duration of battery depletion due to different types of attacks [12]. The simulation work finds a critical point where PV stops to produce necessary voltage for the SEN due to intermittent climate. At this point, SEN is switched to get power from battery. The research proposes to replace the depleted battery, however doing so is not only costly but also troublesome. Besides, it does not provide solution of charging battery for SEN in remote location.

Sensor is used in other fields such as respiratory monitoring system [17]. The author has mainly implemented a prototype to read inductance value of lung phantom conductive material using magnetic sensor embedded Arduino. With the distance variation, irregular respiration patterns are observed. This research has not discussed any power management of the sensor. Katyara, S. et al propose a new architecture called 'SCADA system in-conjunction with WSNs as sensor nodes' for efficient monitoring in SG [2]. In this simulation-based design, SEN are organized in mesh network topology and ZigBee protocol is considered for data transmission. A renewable energy source is integrated for analyzing three scenarios. The state of charge of the battery is observed when the load is fully, partially and completely not supplied by the renewable source. Although the effectiveness of the architecture is verified through hardware implementation, there is a lack of real data analysis on the state of charge of the battery. Software-defined scheme for energy efficient data gathering for WSNs-based SG application is proposed by [18]. In order to improve real time monitoring and control of energy supply in smart cities, the proposed data gathering technique is considered as advanced QoS communication framework. Multi-source energy harvesting mechanisms for WiFi-based SG applications is introduced by the similar authors [19]. The mechanism simulated in EstiNet is a solution energy harvest from the electromagnetic waves that expands the network lifetime of the SEN.

Although different energy harvesting techniques for charging battery have been proposed by researchers, use of solar energy at remote locations is found the most feasible and reliable technique. Many researchers have considered mini PV modules to serve the specific purpose [15, 20-23]. This indicates that choosing right capacity of the PV meets the energy demand and also minimizes the cost of the system. A recent research shows that $80 \%$ performance ratio $(3.93 \mathrm{kWh}$ per $\mathrm{kWp}$ per day) was achieved in Malaysian climate [20]. These researches support to examine the right size of PV for charging battery for SEN application in $\mathrm{SG}$.

Based on our review, many researchers have considered sensor in various applications of SG. However, most of it has not considered the energy management of the sensors under different operating conditions. A few literatures discussed about battery charging status but there is a lack of analysis on the required size of PV for a SEN driven battery in the application of distributed renewable generation. While consider PV as a supplied voltage for charging battery, intermittent climate factor has to take into consideration. It is necessary to battery charging characteristics while it is driving a SEN and being charged 
by a PV simultaneously. For example, a Wi-Fi integrated SEN is placed in the distributed location in the purpose of data collection and transfer. The SEN is powered by PV connected battery. During the data transfer, battery might be drained out but cannot be recharged by PV due to insufficient sunlight. Eventually, the SEN may relent to function.

There are three major pros purposes of charging battery by PV in application of SG. First, the battery should deliver energy or surge operating current to the loads as per its demand. Second, the battery should be charged based on the available solar irradiance. Third, the reliability of system should be maximized by minimizing the risk of undesirable discharge of battery.

\section{PV SYSTEM DESIGN \& METHODOLOGY}

In this section, we have estimated size of battery, PV and other related parameters based on models from other researchers. Then the estimated values are validated by our manual calculation. Sun-hour is obtained from collected data on 2013 by UPM.

\subsection{Battery types}

For the energy storing purpose by solar system, different types of batteries are used; however two most common types are lead-acid and nickel-cadmium cells [24]. Each type of battery has its own characteristics, design, and pros and cons. A suitable type of battery is chosen base on the usability, cost, and requirement. Both types are considered secondary type battery; however, nickel-cadmium battery is superior to lead-acid in term of stand-alone PV system as nickel-cadmium battery has longer life, less maintenance cost, tolerance to extreme discharge etc. The drawback of this type is higher price.

\subsection{ZigBee energy consumption model}

E. Casilari et al. have modeled energy consumption of ZigBee at different stages of its operation [24]. Such stages are considered at consumption when start-up time, association with coordinator, packet transmission, connection lost time, and sleeping mode. However, consumption of these network devices is varied from commercial manufacturing vendors. Table 1. depicts the ZigBee current consumption. If the operating voltage is considered 3.7V (most ZigBee with microcontroller runs at this voltage), power consumption of ZigBee can be calculated at each of its stage of operation.

Table 1. Power consumption at different states of ZigBee module [24]

\begin{tabular}{cccc}
\hline Stage of Operation & Measured current, $(\mathrm{mA})$ & Voltage $(\mathrm{V})$ & Power $(\mathrm{mW})$ \\
\hline Start up & 17.7 & & 65.49 \\
coordinator association & $26.6-33.8$ & & $98.42-125.06$ \\
Packet transmission & 32.5 & 3.7 & 120.25 \\
Connection lost time & $9.3-27.6$ & $34.41-102.12$ \\
Sleeping mode & 0.00075 & & 0.002775 \\
\hline
\end{tabular}

Obtained from datasheet of Arduino UNO, sensors (temperature, humidity and LDR), and ZigBee, the estimated approximate required current consumption for SZA is $95 \sim 100 \mathrm{~mA}$.

\subsection{PV and battery size estimation}

In order to estimate battery and PV size, we analyzed mathematical models which are verified by manual calculation, shown in Table 2. The current consumption for Arduino board with ZigBee radio and three sensors have obtained from datasheet of the respective device. According to the datasheet, the estimated total required current is $50 \mathrm{~mA}$. The SZA is assumed to be active $8 \mathrm{~h} /$ day which yields $2 \mathrm{watt}-\mathrm{h} /$ day.

Two types of lead-acid batteries, such as standard rechargeable and deep cycle AGM type battery are considered. Taking the concern of intermittent solar irradiance availability, minimum 2 days to maximum 5 days of autonomy of battery are considered to ensure the seamless power supply for SZA.

Two types of solar cells are used - crystalline and amorphous silicon thin film solar cell. The experiment was conducted at ALPER, UPM premises and was recorded 3.8-3.9h to achieve 1000Watt $/ \mathrm{m}^{2}$.

Three types of losses are considered, namely cable and connection loss, battery usage constraints, and additional PV panel sizing for compensating power loss. Additional PV panel sizing for compensating power loss and overall system loss are assumed to be $30 \%$ and $10 \%$ respectively. 
Table 2. Estimation on battery and PV size based on climate and SZA power requirement

\begin{tabular}{|c|c|c|c|}
\hline \multicolumn{2}{|c|}{ SZA System } & \multicolumn{2}{|c|}{ Value } \\
\hline Nominal voltage & $\mathrm{V}$ & \multicolumn{2}{|c|}{5} \\
\hline Current consumption & A & \multicolumn{2}{|c|}{0.05} \\
\hline Operating time per day & $\mathrm{h}$ & \multicolumn{2}{|c|}{8} \\
\hline \multirow[t]{3}{*}{ Energy consumption per day } & Watt-h & \multicolumn{2}{|c|}{2} \\
\hline & \multicolumn{2}{|c|}{ Battery Sizing } & \\
\hline & & $\begin{array}{c}\text { Standard lead-acid } \\
\text { battery }\end{array}$ & $\begin{array}{c}\text { Deep-cycle AGM lead- } \\
\text { acid battery }\end{array}$ \\
\hline Preferred days of autonomy & Day & 2 & 5 \\
\hline Actual possible usage capacity & $\%$ & 60 & 60 \\
\hline Total usage in autonomy period & A-h & 0.66 & 1.66 \\
\hline Required capacity with additional $40 \%$ & A-h & 0.924 & 2.32 \\
\hline Required capacity with system loss $10 \%$ & $\begin{array}{c}\text { A-h/ autonomy } \\
\text { day }\end{array}$ & 1.02 & 2.55 \\
\hline \multicolumn{4}{|c|}{ Solar Panel Sizing } \\
\hline & & $\begin{array}{l}\text { IZing } \\
\text { Flexible mono-crystalline }\end{array}$ & A-Si thin film \\
\hline $\begin{array}{l}\text { Average module generating capacity } \\
\text { (peak) }\end{array}$ & $\mathrm{A}-\mathrm{h} / 7 \mathrm{~V}$ module & 0.52 & 0.15 \\
\hline $\begin{array}{c}\text { Average sun-hour recorded at UPM } \\
\text { premises }\end{array}$ & $\mathrm{h}$ & 3.8 & 3.8 \\
\hline Total current per module & A-h/day & 1.98 & 0.57 \\
\hline Total required current from $6 \mathrm{~V}$ battery & A-h/day & 0.33 & 0.33 \\
\hline Module required & Number & 0.2 & 0.58 \\
\hline Considered additional loss margin & $\%$ & 30 & 30 \\
\hline Total module required ( $7 \mathrm{~V}$ each) & Number & 2 & 1 \\
\hline
\end{tabular}

\subsection{Sun-hour Analysis}

We have analyzed solar irradiance data recorded at Universiti Putra Malaysia (UPM) premises. The analysis result is shown in Figure 1. The solar irradiance data is recorded at every half an hour interval from $8 \mathrm{am}$ to $6 \mathrm{pm}$ for $10 \mathrm{~h}$. In each month, we have calculated maximum, minimum, and average sun-hour from measured solar irradiance. The highest average sun hour is achieved in March and the lowest sun-hour is recorded in December. From Figure 1, we have obtained the average sun-hour 3.8h.

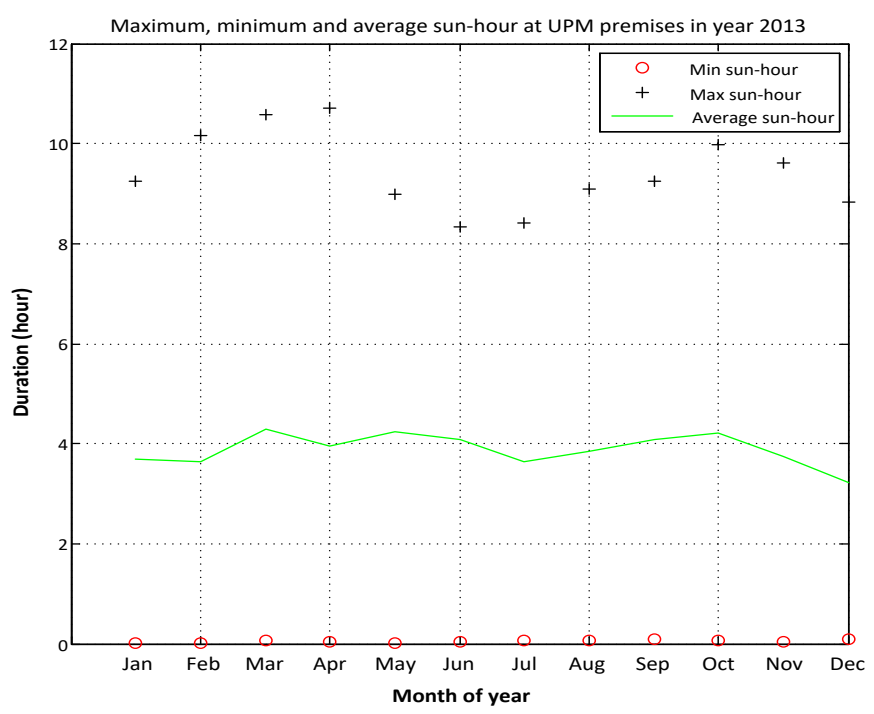

Figure 1. Monthly min, max and average sun-hour at UPM, analyzed from collected data on 2013

\subsection{Deep Cycle and Standard Battery Size Calculation}

Mathematically, we have derived the required size of the battery. The calculation for battery capacity denoted by $C_{B a t t}$ A-h obtained from (1) [25]: 


$$
C_{B a t t}=\frac{\delta \times E_{S Z A}}{\beth \times \varphi \times V_{B a t t}}
$$

The parameters of (1) are: $\delta$ is denoted as the number of autonomous day that battery needs to support $8 \mathrm{~h} /$ day; $E_{S Z A}$ (watt-h) is the energy consumption per day; $工$ and $\varphi(\%)$ are efficiency for battery and inverter respectively; and $V_{B a t t}(\mathrm{~V})$ is the battery nominal voltage. Since the SZA is DC powered, no inverter is used. The value for rest of the parameters of (1) can be obtained from Table 2 which yields minimum required deep cycle and standard battery capacities should be $2.77 \mathrm{~A}-\mathrm{h}$ and $1.11 \mathrm{~A}-\mathrm{h}$. These mathematically obtained results are approximately similar to the manual calculation stated in Table 2.

\subsection{PV Size Calculation}

The suitable capacity for mono-crystalline and thin film PV panels can be obtained from 2 which is stated as follows:

$$
C_{p v}=\frac{E_{S Z A}}{\beth \times \varphi \times S_{\text {hour }} \times(1-\vartheta)}
$$

where $C_{p v}$ (watt-h) peak and $S_{\text {hour }}$ (h) refer PV capacity and total sun-hour of the day respectively. The overall loss calculation and factors that effect on PV generation yield (module surface temperature, possible partial shading, soiling, and tolerance) are denoted as $\vartheta$. Since Malaysia is a tropical country and has always experience of high ambient temperature with cloudy climate, we have calculated the values of $\vartheta$ for monocrystalline and thin film PV are $60 \%$ and $30 \%$ respectively based on our empirical analysis. Therefore, the capacities of mono-crystalline and thin film PV panels can be calculated 2.08 watt-h and 1.19 watt-h respectively. This calculation also supports our manual estimation, referred to Table 2.

\subsection{PV and Battery Configuration}

Based on mathematical analysis as well as manual calculation, the PV panels and batteries are selected whose configurations are mentioned in Table 3 and Table 4 respectively. According to the battery manufacturer, its life span is sensitive to temperature. Since Malaysia's average day time temperature is $35^{\circ} \mathrm{C}$, the battery should be replaced in every 3 years in the context of Malaysia's climate.

Table 3. Crystalline and thin film PV configuration in STC*

\begin{tabular}{ccccccc}
\hline Type of panel & Voc (V) & Isc (A) & Max power (watt) & Efficiency (\%) & Price (unit) & Manufacturer \\
\hline Mono-crystalline & 7.38 & 0.55 & 3 & 12.8 & USD50.5 & Libelium \\
A-Si thin film & 21 & 0.13 & 2 & $4 \%$ & USD22.72 & Solarvoltaic \\
\hline${ }^{*}$ Standard Telo
\end{tabular}

${ }^{*}$ Standard Temperature Condition (STC): $1000 \mathrm{~W} / \mathrm{m}^{2}, \mathrm{AM} 1.5,25^{\circ} \mathrm{C}$

Table 4. Lead acid battery configuration

\begin{tabular}{ccccc}
\hline Type of battery & Capacity & Model & Price & Manufacturer \\
\hline Deep cycle & 6V 2.8Ah & NP2.8-6 & USD20.60 & \\
& & & & \\
Standard & 6V 1.3Ah & MH26866 & USD6.00 & YUASA \\
\hline
\end{tabular}

\section{EXPERIMENTAL SETUP}

The selected PV is connected to the $6 \mathrm{~V}$ battery to monitor its charging characteristics while the battery powers the SZA simultaneously. Across the $6 \mathrm{~V} 1.3 \mathrm{Ah}$ lead-acid battery, we have considered the SZA as a load that monitors data at every $10 \mathrm{sec}$. No sleeping and hibernating mode are considered. The sensors integrated to Arduino are temperature-humidity (HSM-20G) and Light Dependent Sensor (LDR-5527). Figure 3 shows the experimental setup.

Another node, ZigBee assimilated on Waspmote embedded board monitors battery status at every $10 \mathrm{sec}$. Description of two types of nodes is explained in Table 5. Both nodes sent the data to control centre using IEEE802.15.4 supported 2.4GHz ZigBee communication. In the control centre, a LabVIEW based graphical user interface is developed for receiving and further analysis of battery status. Three different types of days were considered, such as sunny-cloudy, fully cloudy, and fully rainy which are denoted as the best, average, and the worst case respectively. 
Table 5. Description on node type

\begin{tabular}{ll}
\hline \multicolumn{1}{c}{ Type of node } & \multicolumn{1}{c}{ Description } \\
\hline SZA or Sensors-ZigBee integrated Arduino & Arduino embedded board, temperature-humidity, and light dependent \\
- considered as SEN or load for the battery & sensors, ZigBee. It reads temperature, humidity, and LDR and sends \\
& to the gateway through ZigBee communication. \\
ZigBee assimilated Waspmote embedded board & Dedicated for monitoring battery status at every 10 sec. \\
\hline
\end{tabular}
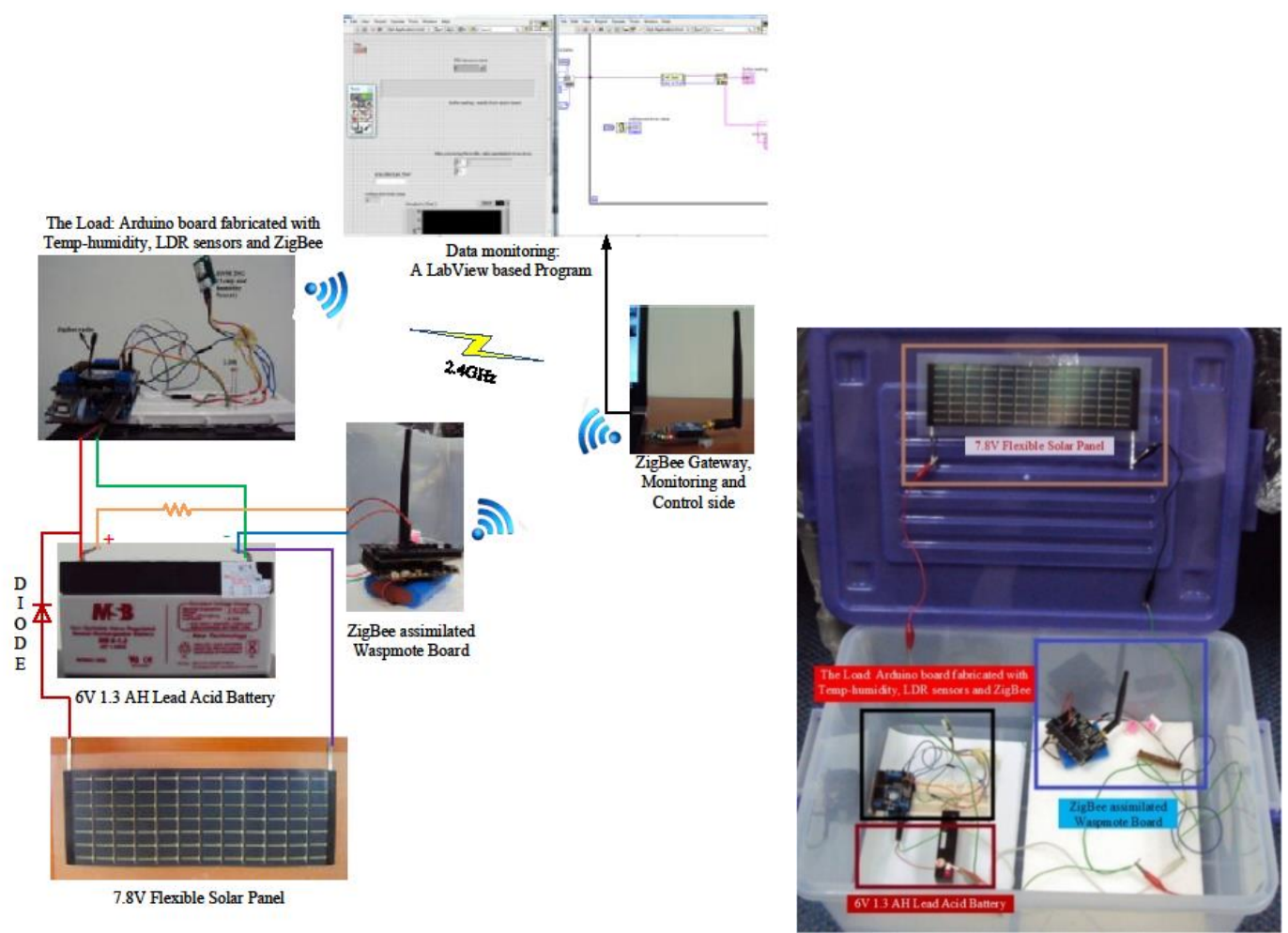

Figure 3. Experimental setup - Lead acid battery powers SZA while it is being charged by PV. The battery status is monitored by a node, called ZigBee assimilated Waspmote embedded board.

\section{RESULT ANALYSIS}

\subsection{Characteristics of Battery Internal Resistance on Average, Cloudy and Rainy Day}

Figure 4(a) shows the characteristic diagram between voltage and internal resistance of the battery while it was being charged by the PV. The average day result illustrates that the internal resistance is truly linear with its voltage. It is similar characteristics to standard internal resistance model. However, the characteristic analyses during cloudy and rainy days show difference. The comparisons among these types of days are depicted in Figure 4(b) and (c) that illustrate internal resistance changes with voltage non-linearly on both cloudy and rainy days. This change occurred between average and cloudy-rainy days due to temperature and solar irradiance variations. The mean solar irradiance was recorded $75.66 \mathrm{~W} / \mathrm{m}^{2}$ on cloudy and rainy day, which is not sufficient to maintain the minimum $6 \mathrm{~V}$ voltage of the battery.

From the analysis of the non-linear behavior of cloudy and rainy days, we can derive the following regression equations:

$$
\begin{aligned}
& \text { [Cloudy]: } f_{\text {cloud }}\left(x_{c}\right)=\alpha e^{\epsilon x_{c}}+\beta e^{\epsilon_{o} x_{c}} \\
& \text { [Rainy]: } f_{\text {rain }}\left(x_{r}\right)=\gamma e^{\tau x_{r}}
\end{aligned}
$$

The constants $\in=-0.753, \alpha=50.21, \beta=17.21, \epsilon_{o}=-0.1289$ for (3) and $\gamma=29.67, \tau=-0.2116$ for (4) are achieved from the regression analysis of Figure 4. Since cloudy or rainy day may appear intermittently, the battery will show the similar characteristics of (3) and (4) for cloudy and rainy day respectively. So, we can construct a periodic extension of $f_{\text {cloud }}$ or $f_{\text {rain }}$ functions using Fourier series, 
called $f^{\prime}{ }_{T}\left(x_{c}\right)$ or $f^{\prime}{ }_{T}\left(x_{r}\right)$ respectively. As the function $f_{\text {cloud }}$ or $f_{\text {rain }}$ can be repeated in every $T$ time interval, first a function $\emptyset(\partial)$ can be defined as (5).

$$
\emptyset(\partial)=\int_{-\infty}^{\infty} f(x) e^{-i \partial x} d x
$$

where $\partial=\frac{2 \pi}{T}$. In the limit, $T \rightarrow \infty$, therefore (6) and (7) can be obtained followed by (5) as follows:

$$
\begin{aligned}
& f_{\text {cloud }}\left(x_{c}\right)=\lim _{T \rightarrow \infty}{f^{\prime}}_{T}\left(x_{c}\right)=\frac{1}{2 \pi} \int_{-\infty}^{+\infty} \emptyset(\partial) e^{-i \partial x_{c}} d \partial \\
& f_{\text {rain }}\left(x_{c}\right)=\lim _{T \rightarrow \infty}{f^{\prime}}_{T}\left(x_{r}\right)=\frac{1}{2 \pi} \int_{-\infty}^{+\infty} \emptyset(\partial) e^{-i \partial x_{r}} d \partial
\end{aligned}
$$

Equation (6) and (7) are the new periodic reconstructed mathematical models of cloudy and rainy days respectively from non-periodic form.

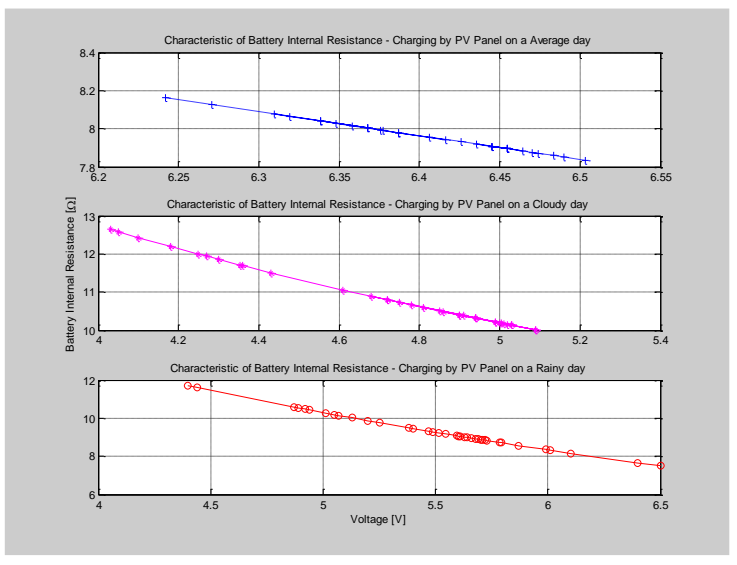

(a)

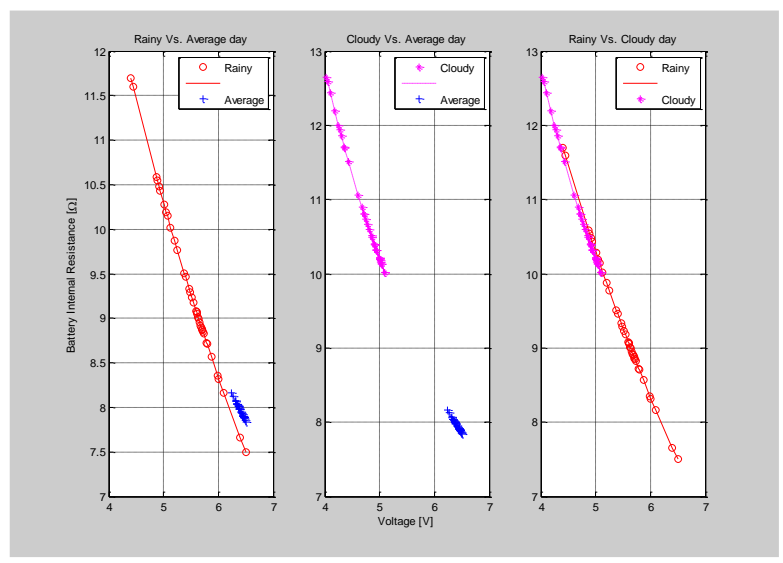

(b)

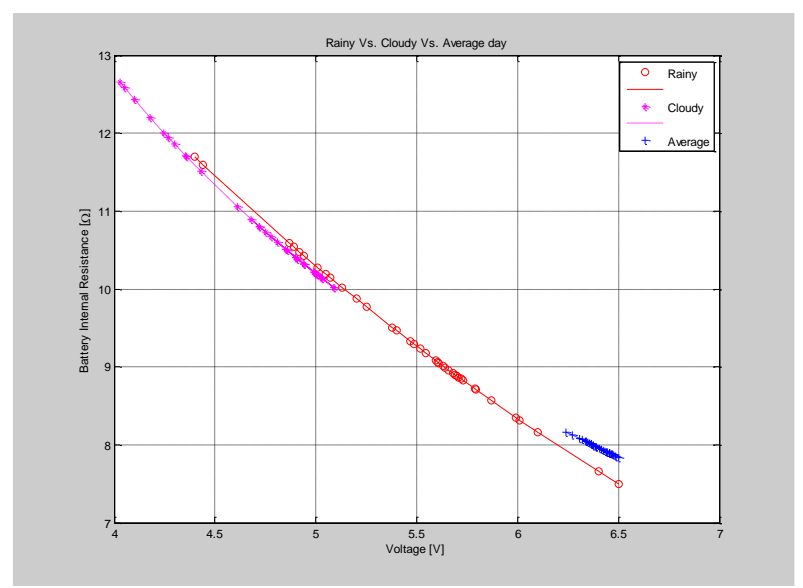

(c)

Figure 4. (a) Characteristics graph of internal resistance vs. voltage; data during battery charge by PV. (b)

Comparison analysis of internal resistance between rainy and average, cloudy and average, and rainy and cloudy days. (c) Comparison analysis of internal resistance among average, cloudy, and rainy days

\subsection{Characteristics of Battery Charging State on Average, Cloudy and Rainy Day}

On the cloudy day, the initial charge of battery was 40-50\% (above $4 \mathrm{~V}$ ) when the experiment was initiated. Data collected on this day from 11:45am to $2 \mathrm{pm}$ shown in Figure 5(a). Since SZA requires minimum $5 \mathrm{~V}$ to operate, it started to function after $12 \mathrm{pm}$ when the charge reached to $5 \mathrm{~V}$. Sometimes SZA stopped working because insufficient voltage of the battery, for instance after $12 \mathrm{pm}$ to $1 \mathrm{pm}$ and $1.50 \mathrm{pm}$ to $2 \mathrm{pm}$. Figure 5(a) shows that the charge of the battery has reached to $5 \mathrm{~V}$ only $24 \%$ of total time, whereas the 
rest of time it was remained within $4 \mathrm{~V}$. If the battery is not fully charged, $7.8 \mathrm{~V}$ PV is unable to recharge the battery up to its full level on the cloudy day.

During the rainy day, the intial voltage of the battery was $5.6 \mathrm{~V}$ and the charging condition of the battery was similar to cloudy day. Since solar irradiance was insufficient, the SZA was switched off manually several times to protect it from under voltage operation. This also helps the battery to be recuperated. Figure 5(b) illustrates the scenario. On the average day, the first half of the day was full sunny and the rest half was fluctuating between sunny and cloudy. The starting voltage of the battery was $6.5 \mathrm{~V}$. The experimental result is shown in Figure 5(c) that states the voltage of the battery did not drop to unable operation state of SZA. The result shows that the PV module is sufficient to charge the battery on this day. Figure 5(c) explores the maximum voltage is obained between $11 \mathrm{am}$ to $1230 \mathrm{pm}$.

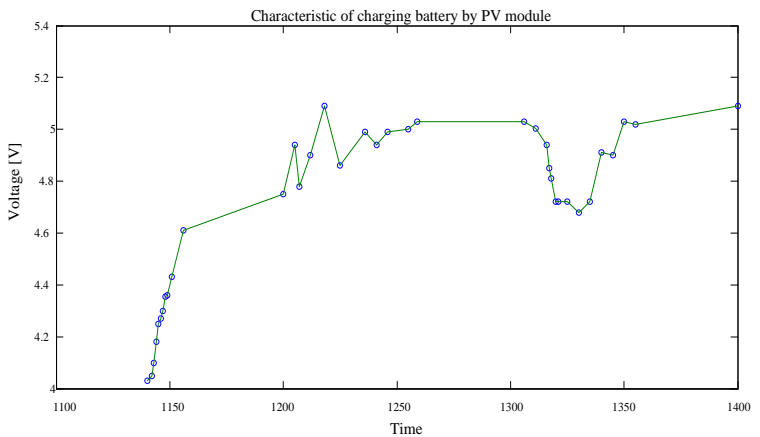

(a)

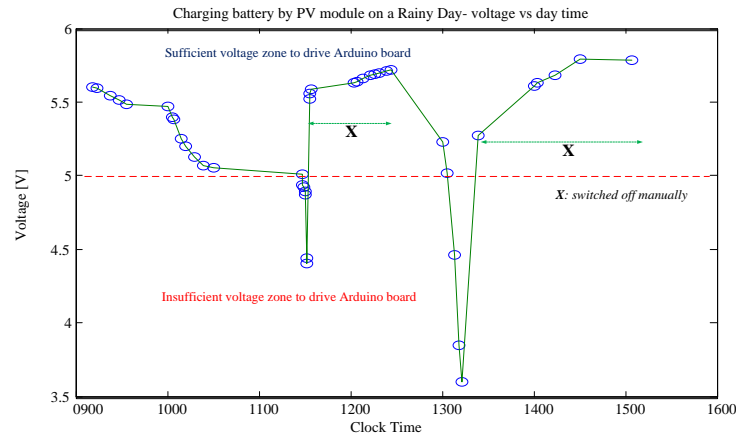

(b)

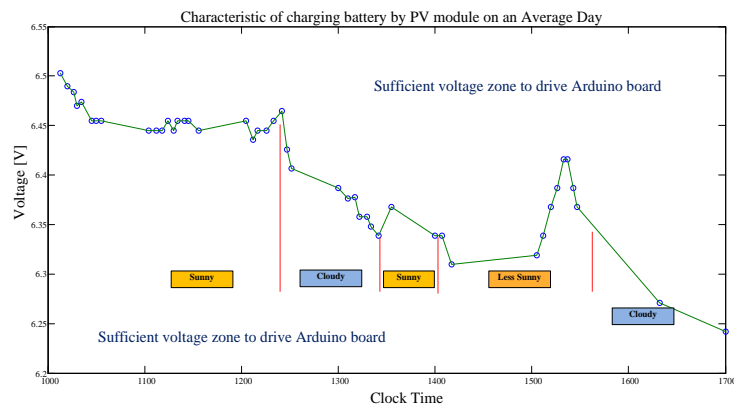

(c)

Figure 5. Charging battery by $7.8 \mathrm{~V}$ PV on (a) cloudy day (11:45am to $2 \mathrm{pm})$; (b) rainy day (9.15am to $3.15 \mathrm{pm})$; (c) average day (10.15am to $5.00 \mathrm{pm})$

\section{CONCLUSION}

This paper presents an experimental data analysis of battery charging characteristics while it is driving a SEN and being charged by a PV simultaneously. The size of the battery and PV were determined from electrical specifications of the SZA, sun-hour data, battery capacity model, and number of autonomous days for battery to support an SEN. The SEN is considered as a load that coalesced Arduino embedded board, temperature-humidity sensor, LDR, and ZigBee radio. The SEN is denoted as SZA which monitors the environmental parameters of the distributed renewable generation site. Another node, Waspmote embedded board and ZigBee radio is used for monitoring the battery status. Both nodes read and send data to the control centre at every $10 \mathrm{sec}$ via ZigBee gateway. At control centre, a LabVIEW based GUI application is implemented to analyse the sensor data received through ZigBee gateway.

The outcome of the research illustrates the battery characteristics on three different days- average, cloudy and rainy day. On the average day, internal resistance of the battery is perfectly linear against its voltage. However, it is quite non-linear on cloudy and rainy days. The regression model equations for cloudy and rainy days are obtained from its single day results. Considering intermittent appearance of cloudy and rainy days all over the year, the equations are further expressed through Fourier periodic series. 
During the real data analysis of the battery charging characteristics, we observed that the selected battery is unable to power continuously to the SZA on cloudy and rainy days. We let the battery charged from $40 \%$ to $85 \%$ of its voltage on cloudy day by the PV before the load SZA is connected to the battery. However, the battery could not power the SZA more than $75 \%$ of total experimental time due to insufficient solar irradiance. On the rainy day, the battery was initially charged at 5.6V. Although the SZA could be powered at the beginning of the experiment, it was switched off several times due to lower than minimum voltage. On the other hand, the SZA was operating on average day without any power failure. The battery always remained at its nominal voltage of $6.25 \mathrm{~V}$, observed from the 7 hours experiment on that day. The battery is sufficient to power the SZA.

For SEN in distributed renewable application in which data transmission from the remote to control centre is not much urgent with the time. Therefore, the considered battery might be used to power the SZA. Increase the PV capacity may solve the cloudy and rainy day charging problem but it will not only be power surplus on average and full sunny day but also costly. Therefore, we suggest improving the battery performance. Through extensive real battery charging characteristics, we expect the mathematical model to serve as a reference for future research in designing an efficient battery in the application of distributed renewable generation.

\section{ACKNOWLEDGEMENT}

The authors would like to thank Geran Putra Berimpak (GPB), University Putra Malaysia for the support by a Research Grant, No. 9671700 and Wong Chai Jen for her contribution in formatting this article.

\section{REFERENCES}

[1] H. Erdem and V. Gungor, "On the lifetime analysis of energy harvesting sensor nodes in smart grid environments," Ad Hoc Networks, vol. 75-76, pp. 98-105, 2018.

[2] S. Katyara, et al., "Monitoring, Control and Energy Management of Smart Grid System via WSN Technology Through SCADA Applications," Wireless Personal Communications, vol. 106, no. 4, pp. 1951-1968, 2018.

[3] S. Zahurul, et al., "Future strategic plan analysis for integrating distributed renewable generation to smart grid through wireless sensor network: Malaysia prospect," Renewable and Sustainable Energy Reviews, vol. 53, pp. 978-992, 2016.

[4] N. Alotaibi, "An Efficient Technique for Reducing Transmission Energy of Sensor Node to Enhance the Lifetime of the WSN's," International Journal of Advanced Trends in Computer Science and Engineering, vol. 8, no. 2, pp. 108-111, 2019.

[5] S. Zahurul, et al., "A novel Zigbee-based data acquisition system for distributed photovoltaic generation in smart grid," 2015 IEEE Innovative Smart Grid Technologies - Asia (ISGT ASIA), pp. 1-6, Nov 2015.

[6] P. Teixidó, et al., "Low-Power Low-Cost Wireless Flood Sensor for Smart Home Systems," Sensors, vol. 18, no. 11, p. 3817, 2018.

[7] H. Singh, V. Pallagani, V. Khandelwal, and U. Venkanna, "IoT based smart home automation system using sensor node," 2018 4th International Conference on Recent Advances in Information Technology (RAIT), pp. 1-5, Mar. 2018.

[8] A. Y. Khang, et al., "Last mile mobile hybrid optical wireless access network routing enhancement," Bulletin of Electrical Engineering and Informatics, vol. 8, no. 1, 2019.

[9] S. Z. Islam, et al., "Communication for Distributed Renewable Generations (DRGs): A review on the penetration to Smart Grids (SGs)," 2012 IEEE International Conference on Power and Energy (PECon), pp. 870-875, Dec 2012.

[10] R. de Souza, et al., "Deploying wireless sensor networks-based smart grid for smart meters monitoring and control", International Journal of Communication Systems, vol. 31, no. 10, pp. e3557, 2018.

[11] N. Saxena, I. Hussain, B. Singh, and A. Vyas, "Implementation of a Grid-Integrated PV-Battery System for Residential and Electrical Vehicle Applications," IEEE Transactions on Industrial Electronics, vol. 65, no. 8, pp. 6592-6601, 2018.

[12] E. Gelenbe and Y. Murat, "Battery attacks on sensors," International Symposium on Computer and Information Sciences, Security Workshop. Springer International Publishing, Feb. 2018.

[13] G. Tuna and V. Gungor, "Energy harvesting and battery technologies for powering wireless sensor networks," Industrial Wireless Sensor Networks, pp. 25-38, Jan. 2016

[14] C. Park, K. Lahiri, and A. Raghunathan, "Battery discharge characteristics of wireless sensor nodes: an experimental analysis," 2005 Second Annual IEEE Communications Society Conference on Sensor and Ad Hoc Communications and Networks, 2005. IEEE SECON 2005., pp. 430-440, Sep. 2005.

[15] W. Guo, W.M. Healy, and M. Zhou, "Battery discharge characteristics of wireless sensors in building applications," Proceedings of 2012 9th IEEE International Conference on Networking, Sensing and Control, pp. 133-138, Apr 2012.

[16] S. Yasin, T. Ali, U. Draz, and A. Rasheed, "Simulation-based battery life prediction technique in wireless sensor networks," NFC IEFR Journal of Engineering and Scientific Research, vol. 6, pp. 166-72, Oct 2018. 
[17] I. Muttakin, D. Abraham, R. Alfanz, and R. Rohmadi, "Respiration Monitoring System of Lung Phantom Using Magnetic Sensor," Bulletin of Electrical Engineering and Informatics (BEEI), vol. 7, no. 1, pp. 15-20, Mar 2018.

[18] M. Faheem, et al., "Energy efficient and reliable data gathering using internet of software-defined mobile sinks for WSNs-based smart grid applications," Computer Standards \& Interfaces, vol. 66, pp. 103341, Apr. 2019.

[19] M. Faheem et al., "Ambient Energy Harvesting for Low Powered Wireless Sensor Network based Smart Grid Applications," 2019 7th International Istanbul Smart Grids and Cities Congress and Fair (ICSG), pp. 26-30, Apr 2019.

[20] T.M. Mansur, N.H. Baharudin, and R. Ali, "A Comparative Study for Different Sizing of Solar PV System under Net Energy Metering Scheme at University Buildings," Bulletin of Electrical Engineering and Informatics (BEEI), vol. 7, no. 3, pp. 450-7, Sep. 2018.

[21] F. Yildiz, "Potential Ambient Energy-Harvesting Sources and Techniques," The Journal of Technology Studies, vol. 35, no. 1, 2009

[22] Z.G. Wan, Y.K. Tan, and C. Yuen, "Review on energy harvesting and energy management for sustainable wireless sensor networks," In 2011 IEEE 13 $3^{\text {th }}$ international conference on communication technology, pp. 362-7, Sep. 2011.

[23] N. Kim and B. Parkhideh, "PV-Battery Series Inverter Architecture: A Solar Inverter for Seamless Battery Integration with Partial-Power DC-DC Optimizer," IEEE Transactions on Energy Conversion, vol. 34, no. 1, pp. 478-485, 2019.

[24] E. Casilari, J. Cano-García, and G. Campos-Garrido, "Modeling of Current Consumption in 802.15.4/ZigBee Sensor Motes," Sensors, vol. 10, no. 6, pp. 5443-5468, 2010.

[25] I. Hadjipaschalis, A. Poullikkas, and V. Efthimiou, "Overview of current and future energy storage technologies for electric power applications," Renewable and Sustainable Energy Reviews, vol. 13, no. 6-7, pp. 1513-1522, 2009. 